Molecules 2002, 7, 817-832

molecules

ISSN 1420-3049

http://www.mdpi.org

\title{
Phytoalexin Accumulation in Colombian Bean Varieties and Aminosugars as Elicitors
}

Diego Durango, Winston Quiñones, Fernando Torres, Yoni Rosero, Jesús Gil and Fernando Echeverri* Institute of Chemistry, Universidad de Antioquia, P.O. Box. 1226, Medellin, Colombia, Tel. (+57) 42105658; Fax: (+57) 4-2330120.

* Author to whom correspondence should be addressed; e-mail: echeveri@catios.udea.edu.co

Received: 1 September 2002; in revised form 15 November 2002 / Accepted 22 November 2002 / Published: 30 November 2002

\begin{abstract}
The accumulation of isoflavonoid phytoalexins was studied in several Colombian bean cultivars resistant and susceptible to Colletotrichum lindemuthianum fungus, the causal agent of anthrachnose disease. A time-course accumulation analysis on seedlings treated with $\mathrm{CuCl}_{2}$ showed that phaseollin production was higher in resistant cultivars than in susceptible ones. Also, a defensive role of phytoalexins was demostrated when extracts containing this pterocarpan exhibited antifungal activity against $C$. lindemuthianum. In addition, the elicitor activity of some aminosugars was also established.
\end{abstract}

Keywords: Phaseolus vulgaris; cultivars; phytoalexins; resistance/susceptibility; elicitors.

\section{Introduction}

Chemical defenses against herbivores and pathogenic microorganisms in leguminosae species include the production of alkaloids, coumarins and specially isoflavonoid derivatives [1,2]. Some of these compounds are phytoalexins, substances produced in plants as a consequence of microorganism attacks and considered one of the most important defensive mechanisms in plants [3]. Recently, a relationship between phytoalexin accumulation and defense against pathogenic microorganisms in 
alfalfa, rice and banana has been found [4-6]. Also, a decreased resistance in Arabidopsis by genetic blockage in the biosynthesis of flavonoids was demonstrated [7]. On the other hand, bean (Phaseolus vulgaris) is an important food and primary source of proteins in Latin America and Africa; many varieties with different phytopathological profiles have been developed around the world. In the species of the genus Phaseolus, representative phytoalexins are isoflavones, isoflavans, pterocarpans (for example, phaseollin), coumestans and isoflavanones (for example, kievitone) [8]. In this paper, we describe the phytoalexin production in several Colombian bean varieties, to establish a correlation between the resistance and susceptibility to Colletotrichum lindemuthianum, the causal agent of anthrachnose disease in bean. In addition, several synthetic aminosugars were also evaluated as elicitors.

\section{Results and Discussion}

Leguminosae species biosynthesize two types of isoflavonoid phytoalexins (Scheme 1) [9]. The first ones are 5-hydroxy compounds such as genistein; through subsequent reactions this compound is transformed to kievitone.

Scheme 1. Biosynthesis of 5-hydroxy and 5-deoxyisoflavonoids

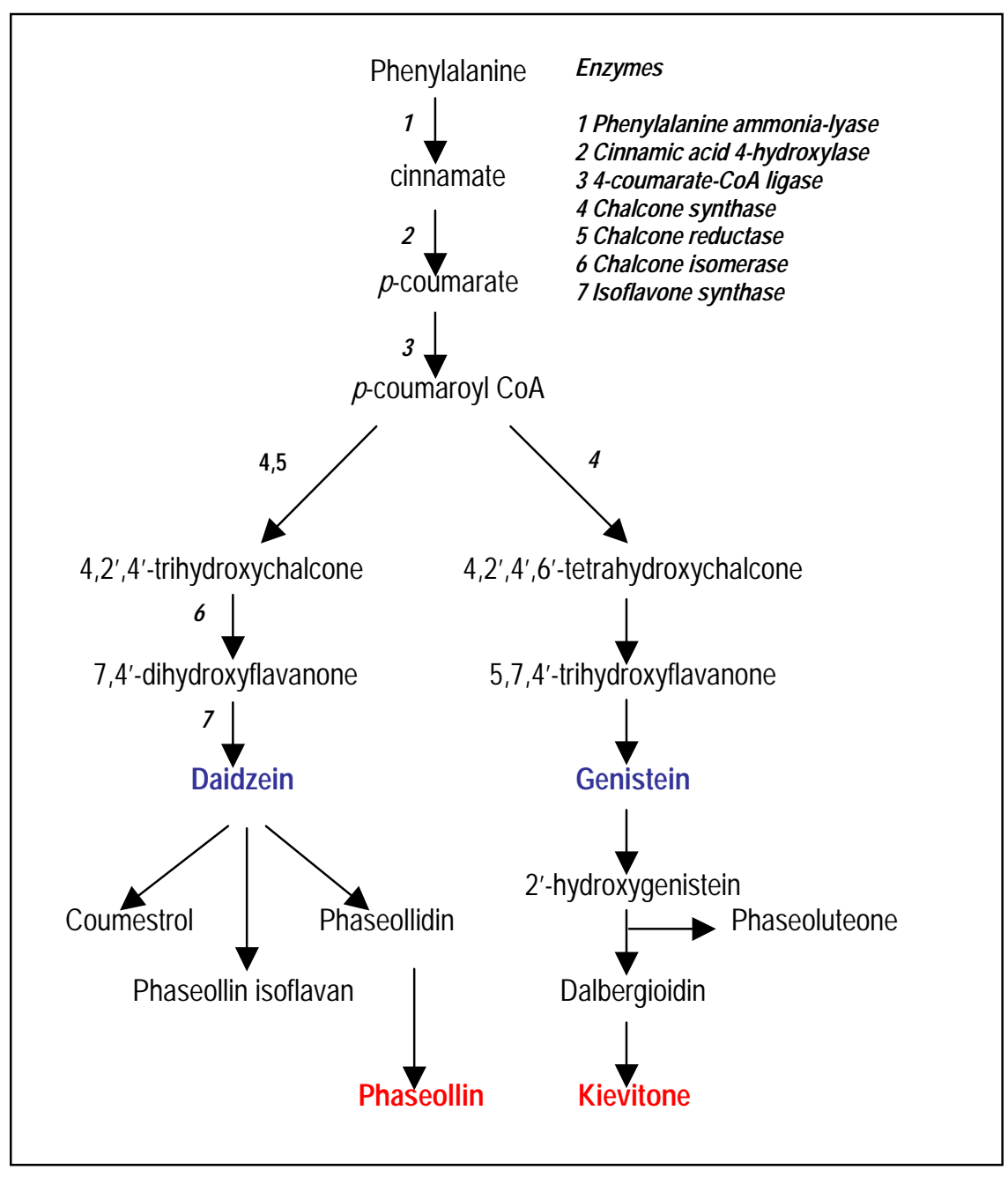


A second type of phytoalexins are the 5-deoxy derivatives and their precursor is daidzein. Cyclization of this compound produces pterocarpans and coumestans. Prenylation of aromatic rings is an additional reaction in bean and soybean phytoalexins. Currently, modulation of the enzymatic and genetic aspects involved in the biosynthesis of phytoalexins is an attractive alternative to fungicide design [10], since increasing phytoalexin production could generate resistant plants against pathogenic microorganisms.

\section{Phytoalexin structures}

All substances were purified by chromatographic methods and identified by ${ }^{1} \mathrm{H}$ - and ${ }^{13} \mathrm{C}-\mathrm{NMR}$ and spectroscopic comparisons with authentic samples. The main compounds obtained were genistein, 2'-hydroxygenistein, daidzein, dalbergioidin, coumestrol, phaseollidin, phaseollinisoflavan and phaseollin (Figure 1); small amounts of genistin and phaseoluteone were isolated too. Phytoalexins were located in the HPLC chromatograms by means of the standard addition method.

Figure 1. Phytoalexins isolated from Colombian bean cultivars.<smiles>[R]Oc1cc([R3])c2c(=O)c(-c3ccc(O)c([R4])c3[R2])coc2c1</smiles>

$\mathrm{R}_{1}=\mathrm{H} ; \mathrm{R}_{2}=\mathrm{H} ; \mathrm{R}_{3}=\mathrm{H} ; \mathrm{R}_{4}=\mathrm{H}:$ Daidzein $\mathrm{R}_{1}=\mathrm{OH} ; \mathrm{R}_{2}=\mathrm{H} ; \mathrm{R}_{3}=\mathrm{H} ; \mathrm{R}_{4}=\mathrm{H}:$ Genistein $\mathrm{R}_{1}=\mathrm{OH} ; \mathrm{R}_{2}=\mathrm{OH} ; \mathrm{R}_{3}=\mathrm{H} ; \mathrm{R}_{4}=\mathrm{H}: 2$ 'Hydroxygenistein $\mathrm{R} 1=\mathrm{OH} ; \mathrm{R}_{2}=\mathrm{H} ; \mathrm{R}_{3}=\mathrm{Glu} ; \mathrm{R}_{4}=\mathrm{H}$ : Genistin $\mathrm{R}_{1}=\mathrm{OH} ; \mathrm{R}_{2}=\mathrm{OH} ; \mathrm{R}_{3}=\mathrm{H} ; \mathrm{R}_{4}=\mathrm{CH}_{2}-\mathrm{CH}=\mathrm{C}\left(\mathrm{CH}_{3}\right)_{2}$; Phaseoluteone<smiles>O=c1oc2cc(O)ccc2c2oc3cc(O)ccc3c12</smiles>
Coumestrol<smiles>CC1(C)C=Cc2c(ccc3c2OC2c4ccc(O)cc4OCC32)O1</smiles>

Phaseollin<smiles>O=C1c2c(O)cc(O)cc2OCC1c1ccc(O)cc1O</smiles><smiles>CC(C)=CCc1c(O)ccc2c1OC1c3ccc(O)cc3OCC21</smiles>

Phaseollidin<smiles>CC1(C)C=Cc2c(ccc(C3COc4cc(O)ccc4C3)c2O)O1</smiles>

Phaseollinisoflavan 


\section{Inductor selection}

Seven-day-old bean seedlings were treated with different abiotic elicitors: $\mathrm{CuCl}_{2}$, chitosan, gentamycin, 6,1',6'-triamino-6,1',6'-trideoxysucrose (saccharosamine), 2-amino-2-deoxy-D-galactopyranose (galactosamine) and 2-amino-2-deoxy-D-glucose (glucosamine) to determine the best response to the accumulation and production of phytoalexins. Preparation of carbohydrate derivatives was carried out according to literature procedures [11,12] and compounds were identified by ${ }^{1} \mathrm{H}-$ and ${ }^{13} \mathrm{C}-\mathrm{NMR}$ techniques. HPLC analysis showed an optimal response with copper (II) chloride (Figure 2), since it quickly induces high concentrations of phytoalexins; other substances, including chitosan, give nearly $50 \%$ of the response obtained with $\mathrm{CuCl}_{2}$ (Figure 3 ).

Figure 2. Effect of $\mathrm{CuCl}_{2}$ in the elicitation of phytoalexins in unelicited (top) and $96 \mathrm{~h}$ elicited (bottom) bean seedlings

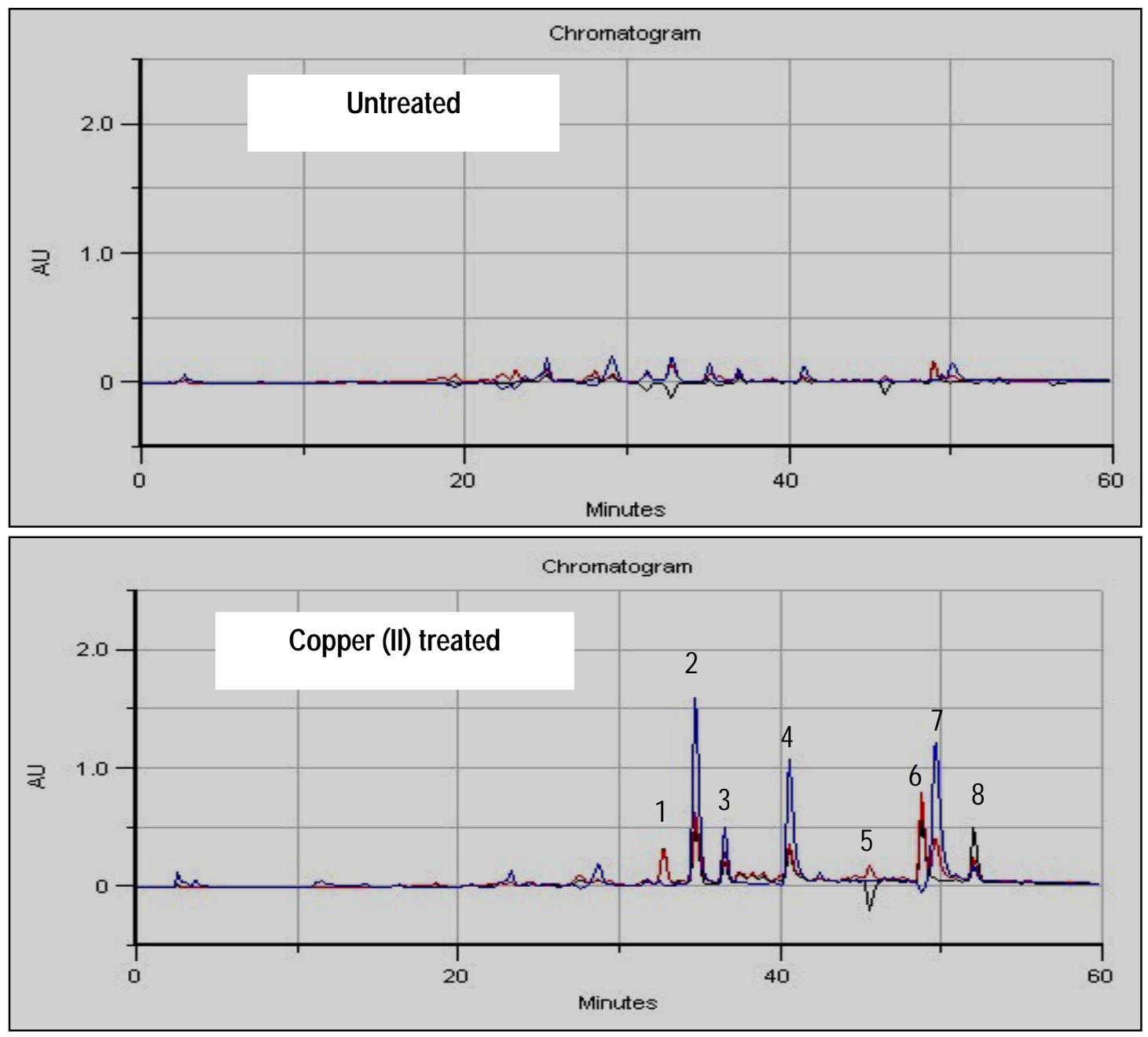

1: Dalbergioidin; 2: 2'-hydroxygenistein; 3: Daidzein; 4: Genistein; 5: Coumestrol; 6: Phaseollidin; 7: Phaseollinisoflavan; 8: Phaseollin. 
Additionally, galactosamine and saccharosamine increased phaseollin and coumestrol concentration close to ten-fold with respect to unelicited seedlings, and as much as chitosan. Gentamycin selectively induced high levels of coumestrol and low levels of phaseollin.

Figure 3. Accumulation of phytoalexins in "Cargamanto Mocho" bean

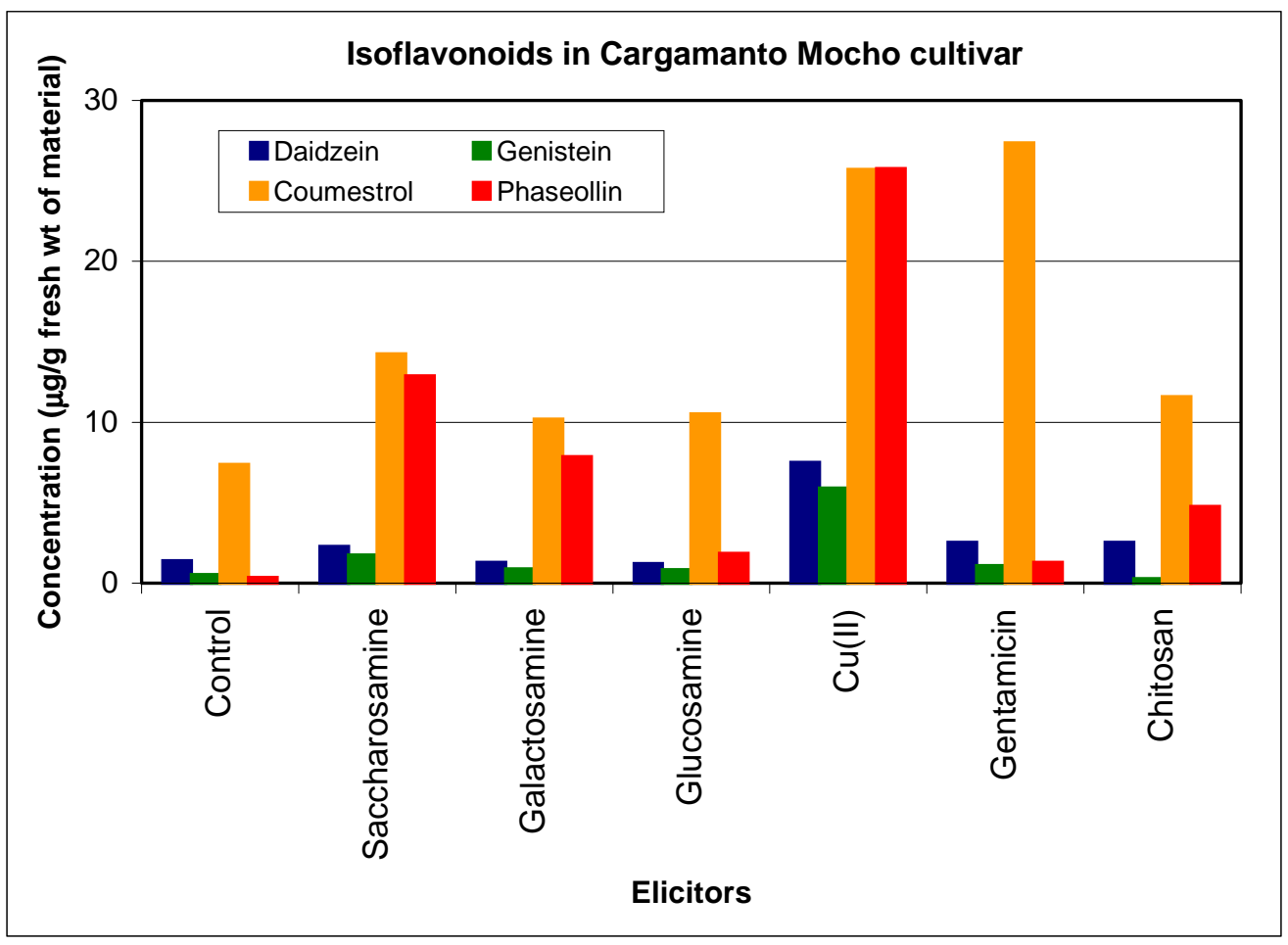

\section{Resistant and susceptible cultivars}

The ability to induce phytoalexin production with $\mathrm{CuCl}_{2}$ was examined in each bean cultivar; isoflavonoid accumulations at 24, 48, 72 and $96 \mathrm{~h}$ after inductor application were analyzed in seedling extracts by HPLC; cultivars induced with $\mathrm{CuCl}_{2}(1000 \mathrm{ppm})$ and not induced $(0 \mathrm{~h})$ were compared

Quantification of phytoalexin production in Colombian beans is shown in Table 1. HPLC analyses showed similar increments in genistein and daidzein concentrations in susceptible and resistant plants. Besides, there are other important features regarding Table 1. In resistant cultivars, preformed coumestrol was close to $60 \%$ higher than in susceptible ones. Nevertheless, after $96 \mathrm{~h}$ of incubation, the concentration of coumestrol was $20 \%$ higher in susceptible cultivars $(104.3 \mu \mathrm{g} / \mathrm{g}$ of f.w.) than in resistant ones $(87.3 \mu \mathrm{g} / \mathrm{g}$ of f.w.). Production of genistein and daidzein increased 24 and 48 hours after incubation; later, there was a slight decrease in concentration. The amount of preformed and induced genistein and daidzein showed no change in both susceptible and resistant cultivars (Figure 4). Furthermore, although there are high levels of genistein, 2'-hydroxygenistein and dalbergioidin, kievitone was not detected by HPLC. This compound is very common in other European and American bean cultivars $[8,13]$. Phaseolutone was detected only in small amounts. 
Table 1. Correlations between phytopathology and production of phytoalexins in Colombian bean cultivars, R: resistent, T: tolerant, S: susceptible to $C$. lindemuthianum.

\begin{tabular}{|c|c|c|c|c|c|c|c|c|c|c|c|c|c|c|}
\hline 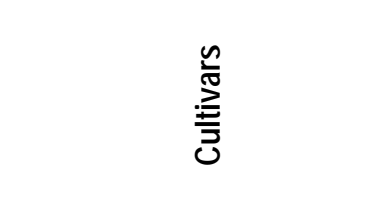 & 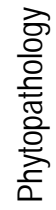 & & 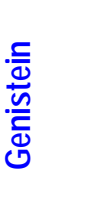 & 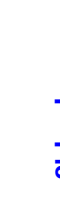 & 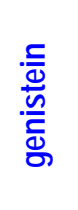 & & 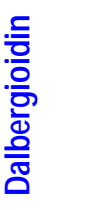 & 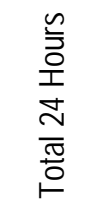 & & סू. & & 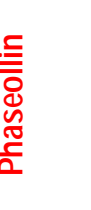 & & 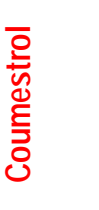 \\
\hline & & \multicolumn{13}{|c|}{ Time after treatment (hours) } \\
\hline & & 0 & 24 & 0 & 24 & 0 & 24 & & 0 & 24 & 0 & 96 & 0 & 96 \\
\hline & & \multicolumn{13}{|c|}{ Relative maximum concentration ( $\mu \mathrm{g} / \mathrm{g}$ of fresh weight) } \\
\hline ICA Calima (CAL) & S & 0.1 & 2.5 & 0.1 & 3.6 & 0.3 & 4.9 & 11.0 & 0.5 & 1.6 & 1.0 & 1.6 & 1.3 & 41.3 \\
\hline Cargamanto Rojo (CRO) & $S$ & 0.1 & 3.1 & 0.2 & 4.4 & 0.4 & 11.2 & 18.7 & 0.5 & 4.4 & 0.6 & 9.8 & 1.9 & 14.0 \\
\hline Cargamanto Mocho (CMO) & $S$ & 0.1 & 2.0 & 0.2 & 3.7 & 0.2 & 3.7 & 9.4 & 0.8 & 3.4 & 0.7 & 20.8 & 1.6 & 14.5 \\
\hline Cargamanto Corriente (CCO) & $S$ & 0.2 & 3.8 & 0.3 & 6.7 & 0.4 & 7.7 & 18.2 & 1.1 & 2.2 & 1.8 & 5.4 & 1.9 & 7.8 \\
\hline Uribe Rosado (URO) & $S$ & 0.1 & 2.2 & 0.2 & 5.8 & 0.1 & 5.1 & 13.1 & 0.6 & 3.8 & 1.2 & 27.4 & 2.1 & 26.7 \\
\hline TOTALS & & 0.6 & 13.6 & 1.0 & 24.2 & 1.2 & 32.6 & & 3.5 & 15.4 & 5.3 & 65.0 & 8.8 & 104.3 \\
\hline ICA Citará (ICl) & $\mathrm{T}$ & 0.2 & 3.4 & 0.2 & 4.6 & 0.5 & 6.0 & 14.0 & 0.8 & 3.9 & 3.3 & 23.3 & 5.1 & 22.8 \\
\hline Quimbaya (IQU) & $\mathrm{R}$ & 0.1 & 3.0 & 0.1 & 5.5 & 0.5 & 5.9 & 14.4 & 0.6 & 4.9 & 0.7 & 14.0 & 1.9 & 17.8 \\
\hline LAS 106 & $\mathrm{R}$ & 0.4 & 2.8 & 0.5 & 3.9 & 1.0 & 2.4 & 11.1 & 1.0 & 3.1 & 4.3 & 65.2 & 1.6 & 19.8 \\
\hline LAS 220 & $\mathrm{R}$ & 0.6 & 4.2 & 0.9 & 7.8 & 0.4 & 11.8 & 23.2 & 1.0 & 3.2 & 6.8 & 28.5 & 4.8 & 26.9 \\
\hline TOTALS & & 1.2 & 13.4 & 1.7 & 21.8 & 2.4 & 26.1 & & 3.4 & 15.1 & 15.1 & 131.0 & 13.4 & 87.3 \\
\hline
\end{tabular}

Figure 4. Time-course study of daidzein content in seedlings of different bean cultivars

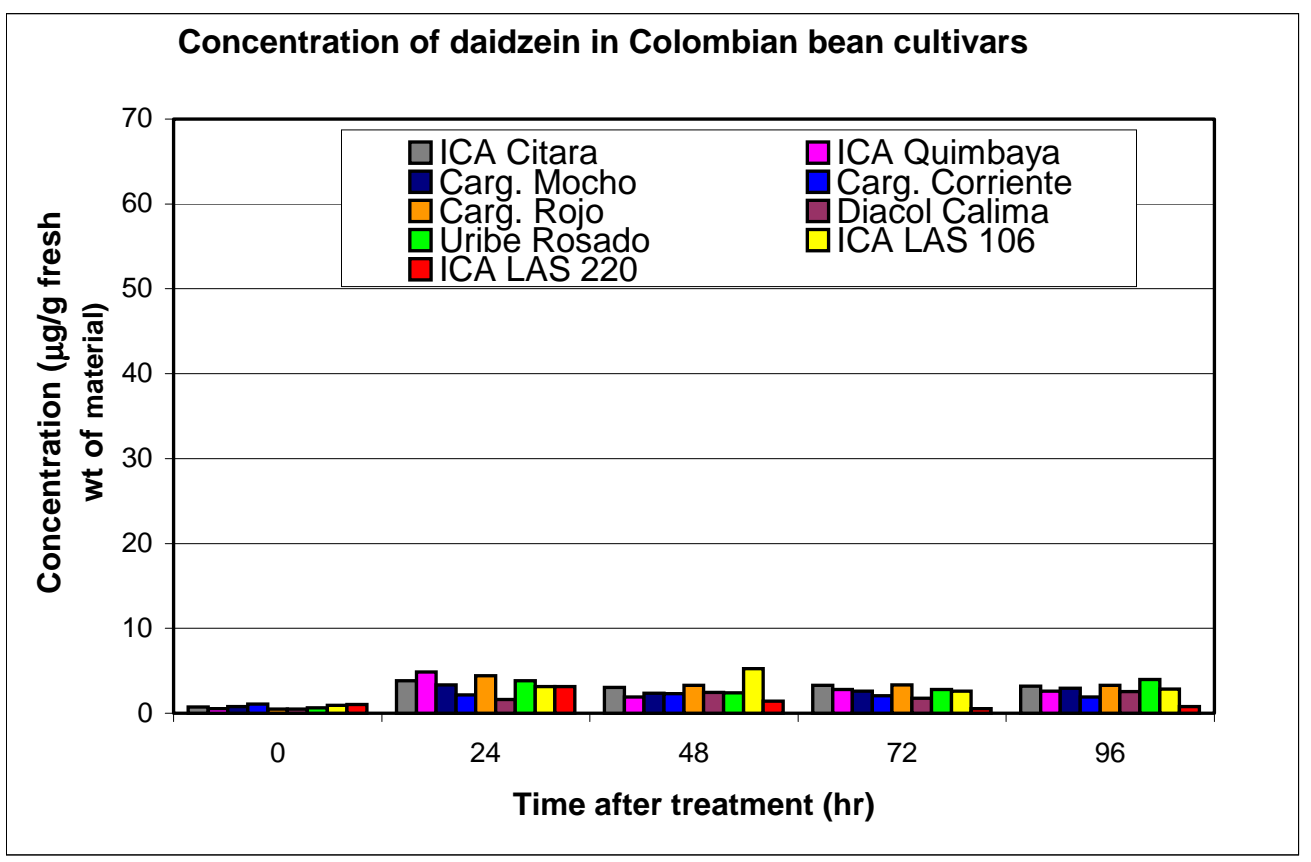


Concerning preformed phaseollin (Figure 5) resistant/tolerant cultivars possess twice the phaseollin as susceptible ones (cf. LAS 220 vs. Cargamanto Rojo). However in the last type of cultivars, phaseollin mainly originated from Uribe Rosado cultivar.

Figure 5. Time-course study of phaseollin content ( $\mu \mathrm{g} / \mathrm{g}$. of f.w.) in seedlings of different bean varieties

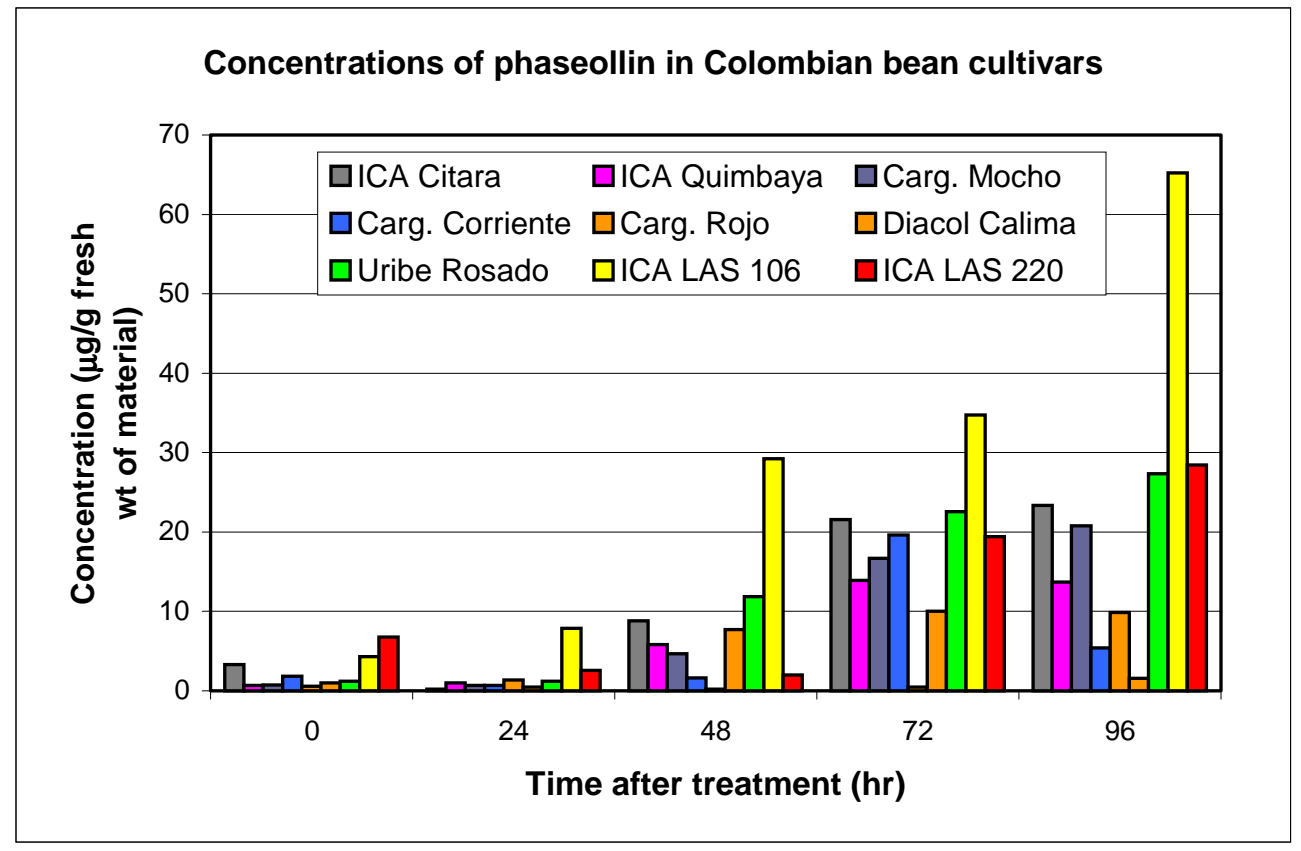

In spite of that, if the contribution of the cultivar Uribe Rosado is excluded, these amounts are practically the same in all cultivars. In addition, the highest level of coumestrol was detected in Calima, a susceptible cultivar, although its level of phaseollin after 4 days was the lowest. Decreased coumestrol levels in resistant varieties could be explained as a consequence of precursor channeling to phaseollin. Treatment with $\mathrm{CuCl}_{2}$ and 96 hours of incubation leads to greater accumulation of this compound in cultivars resistant to anthrachnose (Figures 5-7). However, in Uribe Rosado cultivar, levels of phaseollin were similar to those produced in the LAS 220 resistant cultivar.

Conversion from daidzein to phaseollin seems to be more efficient in the resistant cultivars; this could mean an isoflavonoid enzymatic blockage in cultivars susceptible to $C$. lindemuthianum. Levels of phaseollinisoflavan and phaseollidin were not evaluated because of the presence of interferences with other compounds in HPLC. 
Figure 6. Isoflavonoid contents ( $\mu \mathrm{g} / \mathrm{g}$. of f. w) in seedlings of Cargamanto Rojo bean

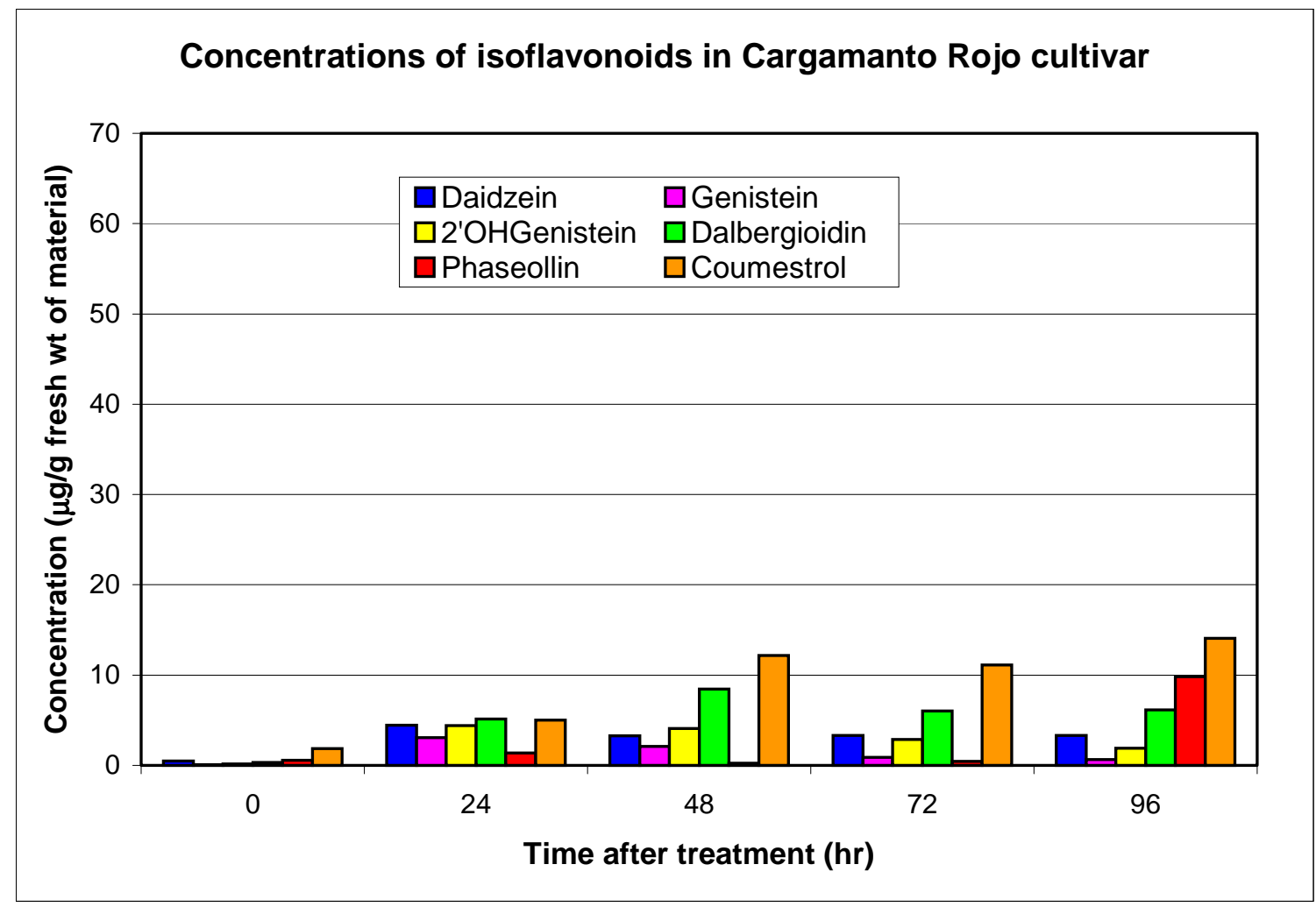

Figure 7. Isoflavonoid contents ( $\mu \mathrm{g} / \mathrm{g}$. of f. w.) in seedlings of Corpoica LAS 106 bean

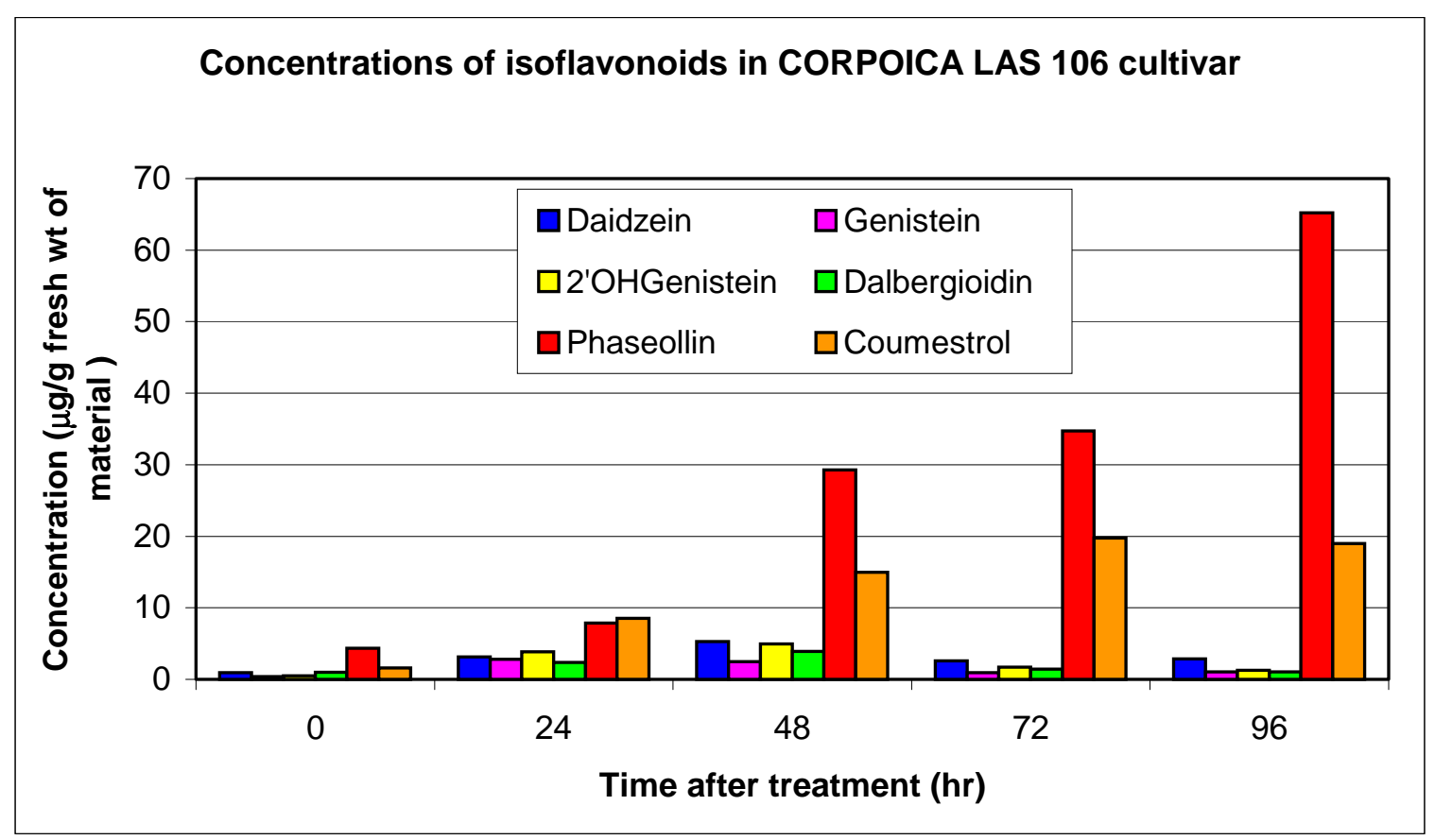


Antibiotic activity

The definition of phytoalexins implies de novo synthesis and antibiotic activity; to determine their action against $C$. lindemuthianum fungus, seedling extracts of some cultivars either treated or not with $\mathrm{CuCl}_{2}$ were studied. Extracts were obtained at $0,24 \mathrm{~h}$ and $96 \mathrm{~h}$ after $\mathrm{CuCl}_{2}$ induction and unelicited seedlings were used as controls (Figure 8). Inhibition of mycelial growth was measured periodically

Figure 8. Antifungal activity of $\mathrm{CuCl}_{2}$ treated-susceptible/resistant bean extracts against Colletotrichum lindemuthianum.

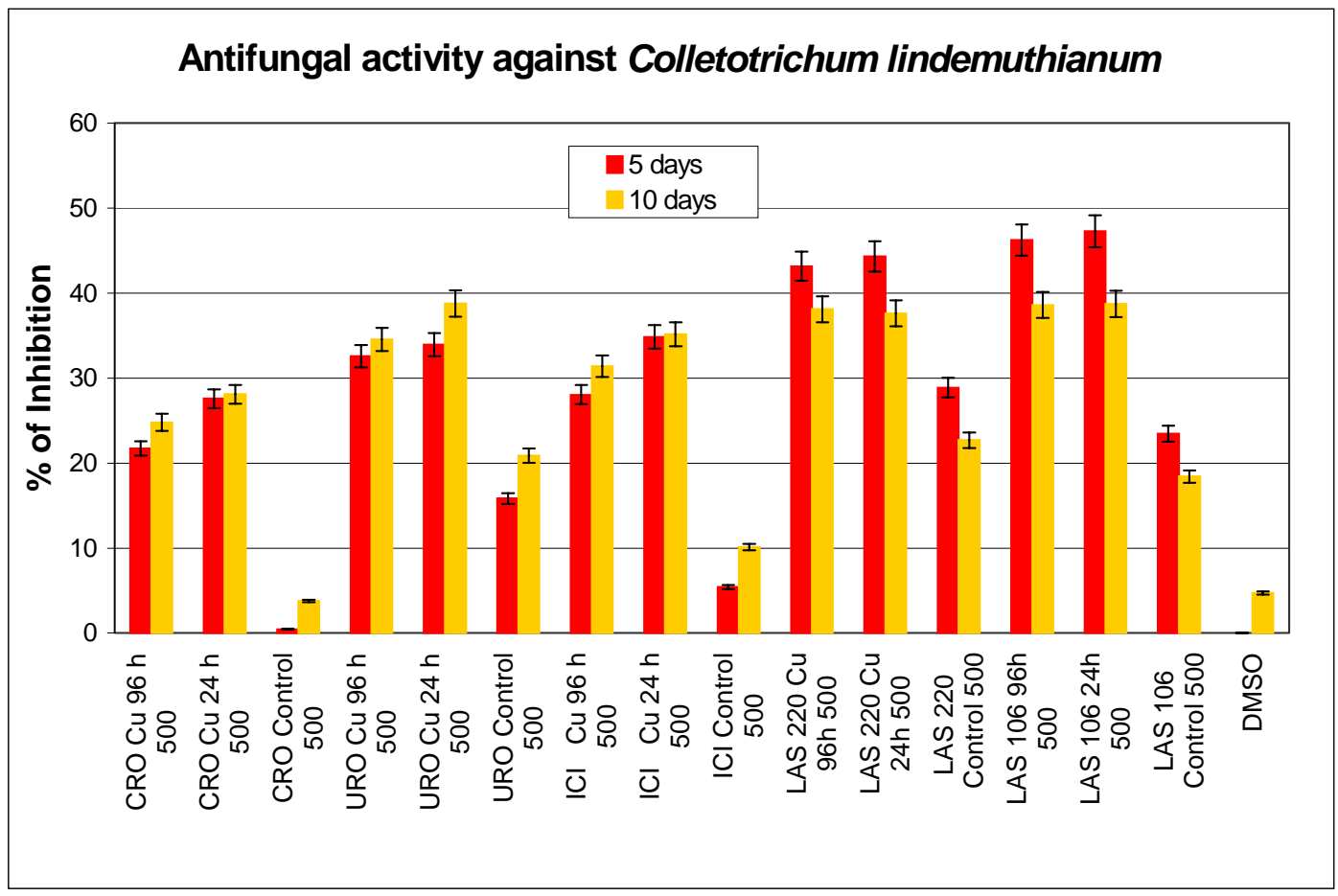

The high antifungal activity of resistant cultivars could be attributed to preformed phaseollin. This compound acts as the first defense until plants biosynthesize more phytoalexins under inductor action. Additionally, extracts of LAS 106 and LAS 220 after 96 h of induction showed high levels of micelar growth inhibition. On the other hand, Cargamanto Rojo (a suceptible cultivar) without $\mathrm{CuCl}_{2}$ treatment displayed weak antibiotic activity, due to the presence of only small amounts of phaseollin. Moreover, a high concentration of coumestrol in susceptible varieties did not appear to contribute to antibiotic activity.

The antifungal patterns of Uribe Rosado cultivar and analysis of phytoalexin levels disagree with its consideration as a susceptible variety; first, it produces more phaseollin and coumestrol than susceptible varieties. Second, it showed antifungal activity higher than Cargamanto Rojo, which is a susceptible variety with low levels of phaseollin production. 


\section{Conclusions}

The results of this research demonstrate a link between phytoalexin accumulation and resistance/susceptibility to pathogenic microorganisms. Thus, ICA Quimbaya cultivar was classified some years ago as resistant but apparently it has lost its phytopathological properties as a consequence of low amounts of phaseollin. Additionally, phytoalexin production in Uribe Rosado cultivar and the antifungal effect of extracts showed a resistant behavior toward $C$. lindemuthianum. There are other examples in the literature [14]: wild varieties of $P$. coccineus displayed high levels of isoflavonoid diversity and resistance to pathogens, while in cultivated species small amounts of phytoalexins were produced. Besides, some varieties of $P$. lunatus have the same resistance and additional cyanogenic compounds, but they did not have isoflavonoid diversity.

High detected levels of coumestrol and its apparent antibiotic inactivity seems contrary to the role of phytoalexins as a defense mechanism against pathogens. Nevertheless, phytoalexins are not only antimicrobial, but rather they can modulate other events related to plant and other plant-organism relationships [15]. These substances can be then chemoattractants, promoters of the competitive growth of other microorganisms, inducing genes involved in bacterial nodulation or regulating the primary metabolism. This could explain the selective response according to the inductor and also the lack of antimicrobial activity of other phytoalexins

The biosynthesis of isoflavonoid phytoalexins has been intensively studied before [16,17]; their metabolic regulation is known to be different according to the inductor agent, plant or cell type. Sometimes PAL activity and phytoalexin production were increased. Nevertheless, it has also been reported that catalytic activity of PAL was not affected, and decreases have been detected too [18]. In this research, we found the same content of genistein and daidzein isoflavones in resistant, tolerant and susceptible cultivars. However, daidzein was transformed efecctively to phaseollin in the resistant cultivars while genistein and dalbergioidin were accumulated in all cultivars but kievitone, the last biogenetic product, was not detected by HPLC. The production of phaseollin and kievitone from isoflavonoids involved prenylation reactions. Our results show an active prenylation pathway in resistant cultivars, while in susceptible ones this enzymatic reaction seems to be repressed. Therefore, enzymatic control in phytoalexins production is located in prenyltransferase reaction instead of phenylalanylammonnia lyase, chalcone synthase or chalcone isomerase.

Finally, protection of bean crops against pathogenic fungi can be achieved through phytoalexin production by means of the following three routes:

- By obtaining clones showing spontaneous phytoalexin production and transfering genes involved in their production from these clones to other cultivars lacking or deficient in phytoalexins. Some genes involved in the biosynthesis of isoflavonoid phytoalexins have already been patented [1920].

- By development of HPLC methodologies to select clones of resistant beans according to the plant's behavior of toward elicitors and phytoalexin levels. 
- By control of the enzymes and genes involved in the phytoalexin production with abiotic elicitors to induce production of antibiotic phytoalexin at a specific time.

Additionally, this research showed the importance of evaluation changes in secondary metabolites in new cultivars or clones, since modifications in their levels of them could have implications in agronomy and public health.

\section{Ackowledgments}

The authors thank COLCIENCIAS and the Universidad de Antioquia for financial support and a grant to D. D. under the Young Researchers program. We are also grateful to Dr. M. Lobo (Corpoica) for a generous gift of bean seeds and Miss Adriana Gallego for microbiological analysis.

\section{Experimental}

\section{General}

${ }^{1} \mathrm{H}-,{ }^{13} \mathrm{C}-\mathrm{NMR},{ }^{1} \mathrm{H}-{ }^{1} \mathrm{H}$ COSY, HMBC and HMQC were recorded on a Bruker AMX 300 spectrometer. Chemical shifts are reported in ppm, units and coupling constants $(\mathrm{J})$ are in Hz. The determination of the carbon atoms in the molecule was made through DEPT 135 and JMOD experiments. HPLC analysis was performed on a Gilson chromatograph equipped with a Gilson model 170 diode array detector, using a Waters Spherisorb S5 ODS2 column (4.6 mm i.d. x $150 \mathrm{~mm}$ ). Elution was carried out at a flow rate of $0.7 \mathrm{~mL} / \mathrm{min}$ with the solvents $\mathrm{A}=$ methanol and $\mathrm{B}=0.5 \%$ acetic acid in water as follows: from $10 \% \mathrm{~A}$ to $70 \% \mathrm{~A}$ in $40 \mathrm{~min}$, then $70 \% \mathrm{~A}$ to $90 \% \mathrm{~A}$ in $20 \mathrm{~min}$, followed by $10 \% \mathrm{~A}$ in $3 \mathrm{~min}$ and holding for $15 \mathrm{~min}$ to equilibrate for the next injection. The wavelength ranged from 200 to $500 \mathrm{~nm}$ throughout the chromatogram and each peak is scanned using the wavelength that provides a maximum response. Preparative HPLC was performed on a column of Lichrosphere ${ }^{\circledR} 100$ RP-18 using a $0.1 \%$ TFA-MeCN, 80:20 mobile phase at a flow rate of 5.0 $\mathrm{mL} / \mathrm{min}$, and detected at 254 and $310 \mathrm{~nm}$.

\section{Plant material}

Seeds of bean cultivars showing resistance to anthrachnose disease (LAS 106, LAS 220 and Ica Quimbaya, IQU), tolerance (Ica Citara, ICI) and susceptibility (Cargamanto Corriente, CCO; Cargamanto Rojo, CRO; Cargamanto Mocho, CMO; Diacol Calima, CAL; Uribe Rosado, URO) were provided by CORPOICA La Selva (Corporacion Colombiana de Investigacion Agropecuaria, Colombia). The seeds were surface-sterilized for 10 min in $1 \% \mathrm{NaOCl}$ followed by a deionized $\mathrm{H}_{2} \mathrm{O}$ rinse and then presoaked in sterile deionized $\mathrm{H}_{2} \mathrm{O}$ for 30 min.; finally the seeds were germinated on sterile sand and grown at $25^{\circ} \mathrm{C}$, ambient humidity and in complete darkness. After 7 days, etiolated seedlings were collected and washed with distilled water and separated into several batches. 


\section{Induction of phytoalexins and elicitor selection}

Approximately $150 \mathrm{~g}$ of the seedlings were immersed for 1 hour in solutions of $\mathrm{CuCl}_{2}(1000 \mathrm{ppm})$, chitosan (Sigma, $1000 \mathrm{ppm}$ ), gentamycin (400 ppm) and aminosugars [6,1',6'-triamino-6,1',6'trideoxysucrose (saccharosamine); 2-amino-2-deoxygalactopyranose (galactosamine); 2-amino-2deoxyglucose (glucosamine)]. Chitosan was solubilized in $1 \%$ aq. HOAc, adjusted to $\mathrm{pH} 6.0$ with $\mathrm{NaOAc}$ and diluted with distilled water to $1000 \mathrm{ppm}$ approximately. Gentamycin solutions were prepared from material supplied by MK Laboratories.

After that, the seedlings were placed in plastic containers and incubated at $25^{\circ} \mathrm{C}$ in the dark during $96 \mathrm{~h}$. Maximum concentration of phaseollin was previously found to be detected between $72-96 \mathrm{~h}$, using $\mathrm{CuCl}_{2}$ as elicitor. Control experiments were carried out using distilled water and the same incubation conditions; experiments were done by triplicate and data were analyzed by one-way analysis of variance (ANOVA)

\section{Isolation and identification of phytoalexins}

For large-scale isolation of phytoalexins, seedlings of each one of the varieties induced with $\mathrm{Cu}$ (II) were combined, cut and milled with $70 \%$ ethanol. Then, the EtOH solution was centrifuged for 6 min (3400 rpm) and filtered through Whatman No. 1 filter paper. The filtrate was concentrated at $40^{\circ} \mathrm{C}$ under vacuum and re-extracted with EtOAc $(3 \times 100 \mathrm{~mL})$. Following evaporation of the EtOAc, the remaining residue was redissolved in hexane- $\mathrm{CH}_{2} \mathrm{Cl}_{2}-\mathrm{MeOH}(2: 1: 1, \mathrm{v} / \mathrm{v})$, filtered and then applied to a Sephadex LH-20 (Pharmacia) column which was eluted initially with the same mixture to remove pigments and finally methanol. The methanolic extract was subjected to chromatography on a silica gel column using hexane containing increasing amounts of EtOAc. Eluates containing phytoalexins were further purified by preparative TLC $\left(\mathrm{CHCl}_{3}\right.$ : acetone, $4: 1 ; \mathrm{Et}_{2} \mathrm{O}$ :hexane, 3:1) and HPLC.

\section{Time course study of phytoalexin production}

Extracts of different cultivars were obtained 24, 48, 72 and $96 \mathrm{~h}$ after induction with $\mathrm{Cu}$ (II) as above. The supernatant was concentrated in vacuo and re-extracted (x 3 ) with an eq. vol. of EtOAc. The samples were kept in a vial and stored at $4^{\circ} \mathrm{C}$ until HPLC analysis was carried out. The Rt values were as follows: genistein, $41.0 \mathrm{~min}$; daidzein, $37.5 \mathrm{~min}$; 2'-hydroxygenistein, $34.2 \mathrm{~min}$; dalbergioidin, $32.0 \mathrm{~min}$; coumestrol, $43.5 \mathrm{~min}$; phaseollin, $52.5 \mathrm{~min}$; phaseollidin, $47.5 \mathrm{~min}$; phaseollinisoflavan, 48.0 min. Calibration curves (peak area vs concentration) for these isoflavonoids were obtained using series of diluted authentic samples. The concentrations of compounds were calculated from the peak areas on the chromatograms and the calibration curves. 
Antimicrobial assays

Colletotrichum lindemuthianum was originally obtained from anthracnose diseased bean pods $(P$. vulgaris) through Corpoica-La Selva. EtOAc extracts of bean seedlings of some resistent and susceptible cultivars, both treated and untreated with $\mathrm{Cu}$ (II), and incubated during 24 and $96 \mathrm{~h}$ were tested in bioassays for fungitoxicity. The extracts were dissolved in DMSO and added to PDA in a concentration of $500 \mathrm{ppm}$. PDA plates containing only DMSO were used as control plates. The radial mycelar growth was measured, and the percentage of inhibition was calculated on the basis of growth in control plates, after 5 and 10 days of incubation at room temperature. The antifungal activity of each extract was replicated five times.

\section{Phytoalexin characterization}

Genistein: HPLC $\mathrm{R}_{\mathrm{t}}=41.0$ min.; UV $\lambda_{\max }(\mathrm{MeOH}-\mathrm{AcOH} 0.5 \%, \mathrm{~nm}): 261,328 \mathrm{sh} ;{ }^{1} \mathrm{H}-\mathrm{NMR}(300 \mathrm{MHz}$, MeOD): $\delta 6.29$ (d, J = 2.3 Hz, H6), 6.42 (d, J = 2.3 Hz, H8), 6.90 (d, J = 8.9 Hz, H3', 5'), 7.46 (d, J = $8.9 \mathrm{~Hz}, \mathrm{H} 2$ ', 6'), 8.17 (s, H2), 13.03 (s, 5-OH). ${ }^{13} \mathrm{C}-\mathrm{NMR}$ (125.8 MHz, MeOD): $\delta 94.1$ (C8), 98.5 (C6), 104.5 (C4a), 115.2 (C5', 3'), 121.5 (C1'), 122.2 (C3), 130.0 (C2', 6'), 153.5 (C2), 157.8 (C8a), 158.0 (C4'), 162.0 (C5), 164.0 (C7), 180.0 (C4).

Daidzein: HPLC $\mathrm{R}_{\mathrm{t}}=37.5$ min.; UV $\lambda_{\max }(\mathrm{MeOH}-\mathrm{AcOH} 0.5 \%$, nm): 238sh, 249, 260sh, 303sh. ${ }^{1} \mathrm{H}-\mathrm{NMR}(300 \mathrm{MHz}, \mathrm{MeOD}): \delta 6.69(\mathrm{~d}, \mathrm{~J}=2.0 \mathrm{~Hz}, \mathrm{H8}), 6.7-6.8\left(\mathrm{~m}, \mathrm{H6}, 3^{\prime}, 5^{\prime}\right), 7.24$ (d, J = 8.7 Hz, H2', 6’), 7.88 (d, J = 8.9 Hz, H5), 8.00 (s, H2). ${ }^{13} \mathrm{C}-\mathrm{NMR}(125.8 \mathrm{MHz}, \mathrm{MeOD}): \delta 102.2$ (C8), 115.1 (C3', 5'), 115.2 (C6), 116.5 (C4a), 122.7 (C3), 123.9 (C1'), 130.0 (C2', 6'), 152.2 (C2), 157.3 (C7, 4'), 157.6 (C8a), 162.6 (C5), 178.6 (C4).

2'-Hydroxygenistein: HPLC $\mathrm{R}_{\mathrm{t}}=34.5$ min.; $\mathrm{UV} \lambda_{\max }(\mathrm{MeOH}-\mathrm{AcOH} 0.5 \%, \mathrm{~nm}): 223.9 \mathrm{sh}, 263.3$; ${ }^{1} \mathrm{H}-\mathrm{NMR}(300 \mathrm{MHz}, \mathrm{MeOD}): \delta 6.29$ (d, J = 2.0 Hz, H6), 6.41 (d, J = 2.0 Hz, H8), 6.41-6.47 (m, H3', 5'), 7.10 (d, J = 8.1 Hz, H6'), 8.14 (s, H2), 12.77 (s, 5-OH); ${ }^{13} \mathrm{C}-\mathrm{NMR}$ (125.8 MHz, MeOD): $\delta 94.3$ (C8), 99.7 (C6), 105.4 (C3'), 107.5 (C4a), 109.1 (C5'), 111.5 (C1'), 123.1 (C3), 132.3 (C6'), 157.4 (C2), 158.2 (C2'), 159.6 (C8a), 161.1 (C4'), 163.5 (C5), 165.9 (C7), 183.1 (C4).

Phaseoluteone: ${ }^{1} \mathrm{H}-\mathrm{NMR}\left(300 \mathrm{MHz}, \mathrm{CDCl}_{3}\right): \delta 1.76$ and 1.85 (s, $\left.\mathrm{CH} 3\right), 3.55\left(\mathrm{~d}, \mathrm{~J}=7.1 \mathrm{~Hz},-\mathrm{CH}_{2}\right.$ ), $5.33\left(\mathrm{t}, \mathrm{CH}=\mathrm{C}\left(\mathrm{CH}_{3}\right)_{2}\right), 6.33$ (d, J = 2.2 Hz, H6), 6.41 (d, J = 2.2 Hz, H8), 6.52 (d, J = 8.4 Hz, H5'), 6.91 (d, J = 8.4 Hz, H6'), 7.94 (s, H2); ${ }^{13} \mathrm{C}-\mathrm{NMR}\left(125 \mathrm{MHz}, \mathrm{CDCl}_{3}\right): \delta 18.1\left(\mathrm{CH}_{3}\right), 23.4(\mathrm{CH} 2), 26.1\left(\mathrm{CH}_{3}\right)$, 94.8 (C8), 100.8 (C6), 106.8 (C4a), 109.8 (C5'), 112.9 (C $\left.\mathrm{C}_{3}\right), 117.6$ (C3'), 122.2 (C10), 124.1 (C1'), 128.4 (C6'), 135.3 (C11), 154.8 (C2'), 155.9 (C2), 157.4 (C4'), 158.4 ( C8a), 163.1 (C5), 163.3 (C7), $181.0(\mathrm{C} 4)$. 
Genistin: ${ }^{1} \mathrm{H}-\mathrm{NMR}(300 \mathrm{MHz}, \mathrm{MeOD}): \delta 8.14$ (s, H2), 7.37 (d, J = 8.6 Hz, H2',6'), 6.84 (d, J = 8.6 Hz, H3',5'), 6.70 (d, J = 2.2 Hz, H8), 6.51 (d, J = 2.2 Hz, H6), 5.05 (2, J = 3.6 Hz, H1-Glu), 3.0-4.1 (m, H2-H6-Glu).

Dabergioidin: HPLC $\mathrm{R}_{\mathrm{t}}=32.0$ min.; UV $\lambda_{\max }(\mathrm{MeOH}-\mathrm{AcOH} 0.5 \%, \mathrm{~nm}): 199,227,287 ;{ }^{1} \mathrm{H}-\mathrm{NMR}$ (300 MHz, MeOD): $\delta 4.27$ (m, H3), 4.60 y 4.44 (m, H2), 5.97 (m, H6, 8), 6.35 (dd, J = 8.3, 2.4 Hz, H5'), 6.45 (d, J = 2.4 Hz, H3'), 6.95 (d, J = 8.3 Hz, H6'); ${ }^{13} \mathrm{C}-\mathrm{NMR}$ (125.8 MHz, MeOD): $\delta 47.7$ (C3), 71.5 (C2), 96.1 (C8), 97.3 (C6), 104.1 (C4a), 104.2 (C3'), 108.3 (C5'), 114.2 (C1'), 132.2 (C6'), 157.5 (C2'), 159.4 (C4'), 165.0 (C8a), 166.1 (C5), 167.5 (C7), 198.9 (C4).

Coumestrol: HPLC $\mathrm{R}_{\mathrm{t}}=43.5$ min.; UV $\lambda_{\max }(\mathrm{MeOH}-\mathrm{AcOH} 0.5 \%, \mathrm{~nm}): 244,342 ;{ }^{1} \mathrm{H}-\mathrm{NMR}(300 \mathrm{MHz}$, MeOD): $\delta 6.95$ (d, J = 2.2 Hz, H4), 7.0-7.1 (m, H2, 8), 7.20 (d, J = 2.0 Hz, H10), 7.78 (d, J = 8.5 Hz, H7), 7.88 (d, J = 8.6 Hz, H1). ${ }^{13} \mathrm{C}-\mathrm{NMR}$ (125.8 MHz, MeOD): $\delta 99.6$ (C4), 103.7 (C6a), 104.2 (C10), 106.2 (C11b), 114.9 (C8), 115.0 (C2), 116.5 (C6b), 122.1 (C7), 123.8 (C5), 156.5 (C4a), 157.9 (C11a), 158.6 (C6), 161.9 (C9), 162.5 (C10a), 162.9 (C3).

Phaseollin: HPLC $\mathrm{R}_{\mathrm{t}}=52.0$ min.; UV $\lambda_{\max }(\mathrm{MeOH}-\mathrm{AcOH} 0.5 \%, \mathrm{~nm}): 279,287 \mathrm{sh}, 310 ;{ }^{1} \mathrm{H}-\mathrm{NMR}(300$ $\mathrm{MHz}, \mathrm{CDCl}_{3}$ ): $\delta 1.49$ (2 x Me), 3.46 (m, H6a), 4.19 y 3.59 (m, H6), 5.44 (d, J = 6.7 Hz, H11a), 5.53 (d, $\mathrm{J}=10.0 \mathrm{~Hz}, \mathrm{H} 13), 6.30(\mathrm{~d}, \mathrm{~J}=8.0 \mathrm{~Hz}, \mathrm{H} 8), 6.36(\mathrm{~d}, \mathrm{~J}=2.5 \mathrm{~Hz}, \mathrm{H} 4), 6.46$ (d, J = $10.0 \mathrm{~Hz}, \mathrm{H} 12), 6.51$ $(\mathrm{dd}, \mathrm{J}=8.4,2.5 \mathrm{~Hz}, \mathrm{H} 2), 6.91(\mathrm{~d}, \mathrm{~J}=8.0 \mathrm{~Hz}, \mathrm{H} 7), 7.37$ (d, J = 8.4 Hz, H1); ${ }^{13} \mathrm{C}-\mathrm{NMR}(125.8 \mathrm{MHz}$, $\left.\mathrm{CDCl}_{3}\right): \quad \delta 28.2(\mathrm{Me}), 29.3(\mathrm{Me}), 40.2(\mathrm{C} 6 \mathrm{a}), 67.1(\mathrm{C} 6), 76.6(\mathrm{C} 14), 79.2(\mathrm{C} 11 \mathrm{a}), 105.0(\mathrm{C} 4), 109.1$ (C10), 110.2 (C8), 113.2 (C2), 117.0 (C11b), 119.5 (C12), 124.2 (C6b), 130.1 (C7), 132.8 (C13), 154.2 (C1), 155.9 (C3), 156.5 (C4a), 157.2 (C9), 157.5 (C10a).

Phaseollidin: HPLC $\mathrm{R}_{\mathrm{t}}=46.5 \mathrm{~min}$.; ${ }^{1} \mathrm{H}-\mathrm{NMR}\left(300 \mathrm{MHz}, \mathrm{CDCl}_{3}\right): \delta 1.85$ y $1.80(2 \mathrm{x} \mathrm{Me}), 3.42(\mathrm{~m}$, H12), 3.59 (m, H6ax), 4.27 y 3.69 (H6), 5.32 (m, H13), 5.51 (d, J = 6.7 Hz, H11a), 6.42 (d, J = 8.0 Hz, H8), 6.47 (d, J = 2.5 Hz, H4), 6.59 (dd, J = 8.4, 2.5 Hz, H2), 7.02 (d, J = 8.0 Hz, H7), 7.45 (d, J = 8.4 $\mathrm{Hz}, \mathrm{H1}) ;{ }^{13} \mathrm{C}-\mathrm{NMR}\left(125.8 \mathrm{MHz}, \mathrm{CDCl}_{3}\right): \delta 23.6(\mathrm{Me}), 26.2(\mathrm{C} 12), 40.5(\mathrm{C} 6 \mathrm{a}), 67.1(\mathrm{C} 6), 78.6(\mathrm{C} 11 \mathrm{a})$, 104.1 (C4), 108.6 (C8), 110.1 (C11b), 110.8 (C2), 113.4 (C10), 119.1 (C13), 121.8 (C6b), 122.7 (C7), 132.8 (C1), 135.4 (C14), 156.3 (C9), 157.0 (C4a), 157.1 (C10a),157.4 (C3).

Phaseollinisoflavan: HPLC $\mathrm{R}_{\mathrm{t}}=48.0$ min.; UV $\lambda_{\max }(\mathrm{MeOH}-\mathrm{AcOH} 0.5 \%, \mathrm{~nm}): 279,287 \mathrm{sh}, 310$; ${ }^{1} \mathrm{H}-\mathrm{NMR}\left(300 \mathrm{MHz}, \mathrm{CDCl}_{3}\right.$ ): $\delta 1.35$ (s, 2 x Me), 2.7-2.9 (m, H4eq and ax), $3.3(\mathrm{~m}, \mathrm{H} 3), 3.91(\mathrm{dd}, \mathrm{J}=$ 10.0, 10.0 Hz, H2ax), 4.23 (dd, J = 10.0, 4.0 Hz, H2eq), 5.59 (d, J = 10 Hz, H11), 6.3-6.4 (m, H5', 6, 8), $6.51(\mathrm{~d}, \mathrm{~J}=10 \mathrm{~Hz}, \mathrm{H} 10), 6.83$ (d, J = 8.0 Hz, H6'), 6.91 (d, J = 8.0 Hz, H5); ${ }^{13} \mathrm{C}-\mathrm{NMR}(125.8$ $\mathrm{MHz}, \mathrm{CDCl}_{3}$ ): $\delta 28.1$ (2xMe), $31.1(\mathrm{C} 3), 32.4(\mathrm{C} 4), 70.5$ (C2), 76.1 (C12), 103.7 (C8), $108.6\left(\mathrm{C}^{\prime}\right.$ '), 109.9 (C3', 6), 115.0 (C11), 116.2 (C1'), 120.0 (C4a), 127.3 (C11), 130.9 (C6', 5), 149.4 (C2'), 152.9 (C4'), 155.4 (C7, 8a). 


\section{References}

1. Hammerschmidt, R.; Schultz, J. Multiple defenses and signals in plant defense against pathogens and herbivores. Recent Adv. Phytochem., 1996, 30, 121-154.

2. Grayer, R. J.; Kokubun, T. Plant-fungal interactions: the search for phytoalexins and other antifungal compounds from higher plants. Phytochemistry, 2001, 56, 253-263.

3. Harborne, J.B. The comparative biochemistry of phytoalexin induction in plants. Biochem. Syst. Ecol., 1999, 27, 335-367.

4. He, X.Z.; Dixon, R. Genetic manipulation of isoflavone 7-O-methyltransferase enhances biosynthesis of 4'-O-methylated isoflavonoid phytoalexins and disease resistance in alfalfa. Plant Cell, 2000, 12, 1689-1702.

5. Dillon, V.M.; Overton, J.; Grayer, R.J.; Harborne, J.B. Difference in phytoalexin responce among rice cultivars of different resistance to blast. Phytochemistry, 1997, 44, 599-603.

6. Otalvaro, F.; Echeverri, F.; Quiñones, W.; Torres, F.; Schneider, B. Correlation between phenylphenalenone phytoalexins and phytopathological properties in Musa and role of a dihydrophenylphenalene triol. Molecules, 2002, 7, 331-340.

7. Glazebrook, J.; Rogers, E.E.; Ausubel, F.M. Isolation of Arabidopsis mutants with enhanced disease susceptibility by direct screening. Genetics, 1996, 143, 973-982.

8. Woodward, M. Phaseollin formation and metabolism in Phaseolus vulgaris. Phytochemistry, 1980, 19, 921-927.

9. Brooks, C., Watson, D. Phytoalexins. Nat. Prod. Rep., 1985, 2, 427-459.

10. Essenberg, M. Prospects for strengthening plant defenses through phytoalexin engineering. Physiol. Mol. Plant Pathol., 2001, 59, 71-81.

11. Khan, R.; Mufti, S.; Jenner, M. R. Synthesis of 1',6,6'-triamino-1',6,6'-trideoxy derivatives of sucrose. Carbohydr. Research, 1973, 30, 183-186.

12. Jarosz, S.; Mach, M. Synthesis of sucrose derivatives modified at the terminal carbon atoms. Pol. J. Chem., 1999, 73, 981-988.

13. Woodward, M. Phaseoluteone and other 5-hydroxyisoflavonoids from Phaseolus vulgaris L. Life Sci., 1979, 2, 680-682.

14. Linding, C.; Benrey, B.; Espinosa F. Phytoalexins, resistance traits, and domestication status in Phaseolus coccineus and Phaseolus lunatus. J. Chem. Ecol., 1997, 23, 1997-2011.

15. Dakora, F.; Phillips, D. Diverse functions of isoflavonoids in legume transcend anti-microbial definitions of phytoalexins. Physiol. Mol. Plant Pathol., 1996, 49, 1-20.

16. Smith, D.A.; Banks, S.W. Biosynthesis, elicitation and biological activity of isoflavonoid phytoalexins. Phytochemistry, 1986, 25, 979-995.

17. Paiva, N. An introduction to the biosynthesis of chemicals used in plant-microbe communication. J. Plant Growth Regul., 2000, 19, 131-143.

18. Afzal, M.; Al-Oriquat, G. Biosynthesis of isoflavonoids and related phytoalexins. Heterocycles, 1982, 19, 1295-1318. 
19. Fader, M. Isoflavone biosynthetic enzymes. U.S. Patent 6,054,636, 2000.

20. Dixon, R.A.; Paiva, N.L.; Oommen, A. Isoflavone reductase promoter, U.S. Patent 5,750,399, 1998.

Sample Availability: Samples are available from the authors.

(C) 2002 by MDPI (http://www.mdpi.org). Reproduction is permitted for noncommercial purposes. 